\title{
Determination of Stress Sources of Social Studies Teacher Candidates
}

\author{
Harun ER ${ }^{1}$, Mehmet Fatih KAYA ${ }^{2}$
}

\section{Summary}

\section{INTRODUCTION}

There exist two basic conditions for stress, described as "disease of the age" and considered as a part of everyday life by various organizations and publications concerning adverse effects since the second half of the 20th century, to emerge. The first one is the uncertainty about the results, and the second is the importance of the results for the individuals (Kara, 2012; Hancock and Desmond, 2001; Krohe, 1999). Stress level may change according to time, space and occupation people have. Though experienced stress may increase or decrease from time to time, it is difficult to say that it completely disappears (Can, 2013:2-3).

This research aims to identify sources of stress for Social Studies teacher candidates. This study is expected to contribute to both the process to take measures regarding the sources of stress and similar research. In this study answers to the following research questions were sought for: 'What are the sources of stress related to (i) the teaching-learning process in undergraduate education, (ii) social life, (iii) personal - family life and (iv) the internship process?' regarding the problem statement "What are the sources of stress for Social Studies teacher candidates?"

\section{METHODOLOGY}

Among the qualitative research approaches, in this research phenomenologic design was used and the data were collected by means of a semi-structured interview technique. The working group was comprised of a total of 54 fourth-grade students studying at the Department of Social Studies Teaching in Siirt University and Abant Izzet Baysal University in 2013 -2014 academic year. This group was determined in accordance with typical case sampling technique. The data obtained were analyzed using content analysis method. Data were encoded separately by each researcher; and differences determined after the comparison of these two coding were rearranged by reference to third expert's opinion.

\section{FINDINGS}

The sources of stress for fourth-grade teacher candidates studying in Siirt University and Abant Izzet Baysal University Faculty of Education Department of Social Studies Teaching were identified in terms of sub-problems about undergraduate education process, social life, personal life and internship process. It was identified that there exist differences as well as similarities in terms of aforementioned sources of stress for teacher candidates studying in both universities.

Social Science teacher candidates consider the following points as sources of stress during their undergraduate education: Often much responsibility assigned to students, preparation process for KPSS, the intensity of the course content and assignments, inefficient lessons, the fact that instructors pay not enough attention to the course and the attitude towards students.

\footnotetext{
1 Assoc. Prof., Bartın University, Faculty of Education, erharun06@gmail.com

2 Assoc. Prof., Siirt University, Faculty of Education, mefkaya@gmail.com
} 
Under the category 'social life', limited social opportunities in the city, anxiety about future, lacking of social awareness, problems with friends, rapidly changing agenda, accommodation and the fact that students can't achieve what they individually consider have been identified as sources of stress.

Regarding the sources of stress Social Studies teacher candidates experience in personal and family life, the fear of being unsuccessful due to environmental expectations, problems experienced with friends, a negative effect of financial difficulties on the courses, pressure the family and the environment form about the future, and anxiety about not reaching the targets for the future were determined as sources of stress.

Regarding the sources of stress experienced in the internship process, Social Science teacher candidates identified overall rapport with the students, supervision problems and personal professional competence, not fulfilling the expectations, feeling nervous while in lecturing and the fact that supervisors do not provide more information about the internship program.

\section{DISCUSSION AND SUGGESTIONS}

It was identified that there exist differences as well as similarities in terms of sources of stress for teacher candidates studying in both universities, regarding their responses to the research questions of the research and suggestions were made in line with these results.

- Determining the level of test anxiety of students and providing support and necessary service can result in positive outcomes.

- Research studies to identify levels of stress for each source and their methods they use to deal with stress can be suggested. Thus, more effective measures can be taken and the recommendations can be improved.

- Delivering training sessions for both students and other stakeholders about the sources and effects of stress, how stress should be managed in order to have a more fruitful university environment.

- Determining the performance criteria for academicians in universities and rewarding those who are successful may result in a positive way to decrease stress, because it will also contribute to the teaching - learning process.

- The fact that universities invest in their development process considering the students' social needs may lead to a reduction in sources of stress regarding insufficient social opportunities in both city and the university.

- Guidance and counseling in school practices may result in positive outcomes.

- Reorganization of hostels and dormitories, run by General Directorate of Higher Education Credit and Hostels Institution, in accordance with recent conditions and increasing the quota can be said to affect student motivation and academic success positively. 